\section{International Scientific Journal Theoretical \& Applied Science}

\author{
p-ISSN: 2308-4944 (print) e-ISSN: 2409-0085 (online) \\ Year: 2015 Issue: 12 Volume: 32 \\ Published: $30.12 .2015 \quad$ http://T-Science.org
}

\section{Sergey Alexandrovich Mishchik}

Associate Professor,

Candidate of Pedagogical Science, Corresponding member of International Academy TAS, Assistant professor Department of Physics, State Maritime University Admiral Ushakov, Russia, sergei_mishik@mail.ru

SECTION 21. Pedagogy. Psychology. Innovation in Education.

\title{
PEDAGOGOMETRIC HOLISTIC DEVELOPMENT OF THE FRAMEWORK FOR ACTION SYSTEM ANALYSIS OF EDUCATIONAL FACILITIES
}

\begin{abstract}
The development of a holistic framework for action pedagogometric systemic analysis of educational facilities through the application of the system of life-term finite twelve stars Ertsgammy as a leading process regarding the psycho-pedagogical activity theory, psycho-pedagogical system analysis and the theory of the formation of mental actions. We consider a detailed system analysis with respect to the integrity of the complexity of educational processes of their formation, the static and dynamic behavior within the adaptive prediction holistic development of educational space.

Key words: pedagogometrics, consistency, integrity, analysis, Ertsgammy star, forming, adaptive prediction, educational space.

Language: Russian

Citation: Mishchik SA (2015) PEDAGOGOMETRIC HOLISTIC DEVELOPMENT OF THE FRAMEWORK FOR ACTION SYSTEM ANALYSIS OF EDUCATIONAL FACILITIES. ISJ Theoretical \& Applied Science 12 (32): 71-80.

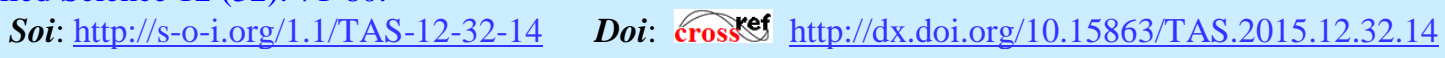

УДК 372.851

\section{ЦЕЛОСТНОЕ РАЗВИТИЕ ПЕДАГОГОМЕТРИЧЕСКОЙ СТРУКТУРЫ ДЕЙСТВИЙ СИСТЕМНОГО АНАЛИЗА ОБРАЗОВАТЕЛЬНЫХ ОБЪЕКТОВ}

Аннотация: Предложено иелостное развитие педагогометрической структуры действий системного анализа образовательных объектов системной жизнедеятельности через применение двенадцати конечной звезды Эризаммы в качестве ведущчего прочесса относительно психологопедагогической теории деятельности, психолого-педагогического системного анализа и теории формирования умственных действий. Рассматривается детальная целостность системного анализа относительно развития сложности педагогических процессов, их формообразования, статического и динамического поведения в рамках адаптивного прогнозирования иелостного развития образовательного пространства.
\end{abstract}

Ключевые слова: педагогометрика, системность, целостность, анализ, звезда Эризгаммы, формообразование, адаптивное прогнозирование, образовательное пространство.

Целостное развитие педагогометрической структуры действий системного анализа образовательных объектов устанавливает определяющее направление в моделировании и исследовании учебно-профессиональной деятельности относительно широкопрофильной направленности современного политехнического производства. Совместно с психологической теорией деятельности и теории формирования интеллекта последовательность целостно- системных действий системного анализа формирует методологический подход к организации и совершенствовании всего учебновоспитательного процесса. Продолжим рассматривать структуру каждого действия системного анализа относительно его ориентировочной, исполнительной и контрольной компоненты, отражающих их целостное развитие в различных формах учебно- 
профессиональной деятельности и этапах познавательного процесса.

Действие седьмое. Определить системообразующие связи уровня системы.

Психолого-педагогический системный анализ определяет базисную установку и формирует условия подготовки специалиста широкого профиля - формы развития целостносистемного учебного процесса. Седьмым базисным действием психолого-педагогического системного анализа является процесс по определению системообразующих связей уровня системы.

Системообразующие связи уровня системы, в первую очередь, обеспечивают процесс переноса функции системы на данном уровне анализа формирования заданной целостности объекта. Данное явление в период проектирования функции отражает как начальные условия процесса передачи, так и его конечные результаты. Своеобразие «чёрного ящика» раскрывается в процессе представления порождающей среды, целостных свойств объекта, его формы существования, характера сложности, разнообразия и упорядоченности, а также поведения системы и прогноза развития самой системообразующей связи.

Системообразующая связь обладает многими атрибутами, связанными как с характеристиками деятельности, их предметными условиями, информационными параметрами, а также уровнем адаптивности в развивающей системе. Выделенные направления анализа позволяют организовать функционирование объекта от его элементарного поведения (статической статики) до абсолютного управляемого состояния в условиях динамической динамики - сверх хаоса. Это формируется через организацию процесса близкодействия, когда близлежащая функция формируется по принципу «первого типа ориентировки». Развитие уровня скоростной связи задаёт новые схемы «оперативного мышления», направленные на проектирование совершенных типов ориентировки в условиях неопределённости и нечёткости.

Развитие структуры системообразующей связи должно отражать три базисных принципа: гомеоморфизма, рефлексии

полифункциональности. Гомеоморфизм задаёт не просто копирование и перенос состояния или функции системы, а устанавливает единство структур, процесса и развитие объекта. Заданный «запас гомеоморфизма» определяет целостные характеристики системообразующей связи относительно её пространственности, энергетичности, гравитационности, силовых и временных характеристик [1].
Принцип рефлексии системообразующей связи задаёт не только возможность многократного применения данной связи в различных ситуациях поведения системы, но и возможность изменять направление переносимой функции особенно при реализации процесса «смещения» предметных условий. Принцип поли функциональности системообразующей связи позволяет развить принцип суперпозиции относительно выделенного пространственного, временного, энергетического, гравитационного и силового параметров. Возникающие новые виды и формы системообразующих связей регламентируются возможностями формирования новых структур, которые отражают многомерный характер состояния и развития целостносистемного цикла жизнедеятельности.

$$
\text { При этом целостно-системные }
$$

функциональные связи обладают характеристиками обобщённости, развёрнутости, системности, широкопрофильности, автоматизацией. Все данные характеристики отражают уровень сформированности соответствующего процесса ориентировки в методах переноса функции относительно выделенного этапа существования психологопедагогического системного анализа. Установленные этапы формирования целостносистемного знания в формах: ориентационного, мотивационного, визуального, акустического, калориметрического, термодинамического, обонятельного, материального, рецепторного, речевого, письменного , внутреннего - отражают целостно-системную основу развития системообразующих связей.

Развитие облачных технологий в образовательных процессах определяют новые формы системообразующих связей, когда выделенные условия хранения и передачи информации принимают инновационный характер. При этом процесс переноса информации и качества жизнедеятельности задают соответствующий градиент системообразующей связи. Скорость совершённого действия и процесс отладки программного продукта определяются уровнем синхронизации всего множества каналов отношений между структурными элементами целостно-системных циклов жизнедеятельности относительно общей функции.

Поведение целостно-системных смыслообразующих связей определяется формой проведения переноса информации и действия. Достоверность передачи информации, её сохранение и переработка в определённых количествах и формах определяется цепочкой отдельных операций психолого-педагогического системного анализа, выполняемых с определённым уровнем автоматизации. 
Существующие внутренние микроциклы действия относительно ориентировки, исполнения и контроля определяют дифференциальные формы системообразующих связей. При этом, возникающие новые системные отношения, принимают и интегральные формы, то есть возникают связи отражающие глобальные характеристики представленных информационных блоков и заданных схем.

Наивысшим уровнем формирования системообразующих связей можно выделить индукционный способ их организации. Он возникает в системных организациях и циклах при нейронном моделировании образовательных процессов. Возникающие связи формируются в процессе создания автоматизированных учебных комплексов, когда новая связь образуется в процессе установления элементарных действий системного анализа относительно выделенных стандартных логических операций. Самонаводящиеся связи есть продукт нормативного составления учебного материала относительно заданного алгоритма учебной деятельности широкопрофильного специалиста в условиях абсолютной автоматизации полного жизненного цикла производства заданного образа.

Действие восьмое. Установить межуровневые системообразующие связи системы.

Психолого-педагогический системный анализ задаёт базисную установку и определяет условия формирования специалиста широкого профиля - смысла функционирования целостносистемного учебного процесса. Восьмым базисным действием психолого-педагогического системного анализа является процесс по установлению системообразующих связей системы.

Межуровневые системообразующие связи системы (МССС), в первую очередь, устанавливают процесс переноса функции системы от данного уровня анализа формирования заданной целостности объекта до необходимого вышестоящего или микроуровня. Процесс переноса функции имеет поэтапный характер преобразования интегральных характеристик в наиболее элементарные, дифференциальные моменты развития заданной функции. При этом межуровневые системообразующие связи обеспечивают два противоположных по отношению к любому структурному элементу моменты интериоризации и экстериоризации результатов полученных качеств учебно-профессиональных знаний и умений широкопрофильного специалиста [2].

МССС обеспечивают общее синхронное развитие целостно-системного цикла жизнедеятельности (ЦСЦЖ) относительно каждого элемента цикла. При этом, при переходе на более скоростные качества функционирования ЦСЦЖ наблюдается процесс переключения связей на структурных элементах уровня при смещении предметно-деятельных элементов. Это позволяет управлять развитием МССС в зависимости от характера развития системы относительно её целостности. На первых этапах развития МССС формируются отношения между предметными условиями: субъектами, технологическими средствами, предметами, продуктами, опредмеченными потребностями, компаунд-субъектами и супер субъектами.

На последующих этапах развития происходит формирование МССС относительно деятельностных структурных элементов. Данный процесс имеет аналогичную технологию относительно развития сложности межуровневых отношений. То есть, развитие межуровневых связей имеет трёхфазную структуру относительно ориентировочной, исполнительной и контрольных компонент деятельности. Ориентировочная межуровневая связь имеет обще смысловое значение относительно дальнейшего наращивания заданного типа отношений. Именно данный компонент деятельности закладывает базисную структуру развития всей МССС заданной функции относительно всех последующих элементов развивающейся структуры.

Развитие ориентировочного компонента заданного типа ориентировочной основы МССС имеет многотиповую структуру от первого типа, когда формируемые связи базируются относительно элементарного алгоритма действия к целостно-системному, мульти циклическому типу. Данный тип структуры имеет многоуровневую горизонтальную структуру, ширина которой определяет размерность ячейки «внутри уровневый-межуровневый компонент» связи (ВМКС). Обмен данными компонентами определяет подвижность и мобильность структуры всего ЦСЦЖ. Множество ВМКС формируют базисные составляющие многомерных циклов жизнедеятельно относительно всех видов профессиональной деятельности заданного типа широкопрофильного образца.

При дальнейшем развитии МССС формируются рефлексивные составляющие: исполнительные и контрольные ячейки ВМКС, которые имеют соответствующие структуры относительно цели существования и развития самих межуровневых связей и отношений. В целом, можно определить три базисных вида MCСС относительно структуры ЦСЦЖ, предметно-деятельностного системного анализа и формы существования самого целостносистемного цикла. 
Межуровневые системообразующие связи системы относительно структуры ЦСЦЖ имеют двенадцать типов связей по установлению многоуровневого функционирования начального субъекта, всеобщей деятельности, средств деятельности, технологической деятельности, предмета деятельности, контрольной деятельности, результата (продукта) деятельности, ритуальной деятельности, опредмеченной потребности, восходящей деятельности, компаунд-субъекта, деятельности развития и нового типа суперсубъекта. Все МССС имеют трёхуровневую горизонтальную структуру относительно формирования ориентировочного, исполнительного и контрольного компонента заданного типа ориентировочной основы от рецептурного до целостно-системного.

Межуровневые системообразующие связи системы относительно собственно системного психолого-педагогического анализа ЦСЦЖ также имеют двенадцать типов связей определяемых по: выделению объекта как системы, установлению порождающей среды, определению целостных свойств системы, выделению уровней анализа, установлению структурных элементов уровня, определению внутри уровневых системообразующих связей, выделению межуровневых системообразующих связей, установлению формы организации, определению системных свойств, выделению характера поведения и установлению перспективы развития цикла.

Межуровневые системообразующие связи системы относительно этапа формирования ЦСЦЖ также имеют двенадцать типов связей определяемых по: ориентационному этапу, мотивационному этапу, визуальному этапу, акустическому этапу, калориметрическому этапу, термодинамическому этапу, обонятельному этапу, материальному этапу, рецепторному этапу, речевому этапу, письменному этапу, внутреннему этапу. Все МССC имеют трёхуровневую горизонтальную структуру относительно формирования ориентировочного, исполнительного, контрольного компонента заданного типа ориентировочной основы от рецептурного до целостно-системного смыслообразующего значения.

Действие девятое. Определить форму организации системы.

Психолого-педагогический системный анализ выражает базисные условия и задаёт процесс формирования специалиста широкого профиля - формы организации целостносистемного учебного процесса. Девятым базисным действием психолого-педагогического системного анализа является деятельность по определению формы организации системы.
Форма организации системы (ФОС), в первую очередь, определяет процесс переноса многоуровневого содержания объекта в виде структурных элементов и многочисленных межуровневых и внутри уровневых системообразующих связей во внешнюю явную форму системы. При этом подчёркивается именно системная форма, которая формировалась из начальных системных представлений выделенных в виде восьми основных целостных свойств: временных, энергетических, гравитационных, силовых, пространственных, ориентационных, исполнительных и контрольных - определённых в конкретной порождающей среде, заданных уровнем анализа системы, а также её структурными элементами и характеристиками системообразующих связей.

Дальнейшая системная организация исследования объекта порождает особенные характеристики формообразования, которая отражается: в общей тематике анализа проблемы исследования, изменении внутренней логической структуры, выделении новых структурных элементов и образовании специальных системообразующих связей направленных на фиксацию особенных форм.

Следующий этап формообразования стремится выразить одновременно особенные направления исследования. Первое, выражение целостно-системного характера самого процесса учебно-профессиональной деятельности. Второе, системная форма самой широкопрофильной деятельности, как реализация системной ориентировки во всех видах предметных условий и собственных связей между ними. При этом форма организации всего цикла жизнедеятельности зависит от уровня выделенного типа ориентировки, исполнения и контроля. Все основные предметные условия характеризуются заданными типами ориентировки, которые порождают определённые формы профессиональной и учебной деятельности.

Процесс формообразования в значительной мере определяется структурой анализа объекта. Системный анализ производит новые формы, которые задаются особенным содержанием учебно-профессиональной деятельности. Они наполняются различными прикладными формами действий системного анализа направленных на: выделение первичных системных особенностей объекта; определение порождающей формы окружающей среды; представление внешних форм целостных характеристик объектов; выделение формообразующей иерархии уровней анализа объекта; определение формы структуры анализа системы; представление формы структурных элементов заданного уровня; выделение формы внутри уровневой 
системообразующей связи; определение формы межуровневой системообразующей связи; представление интегральной и дифференциальной формы существования самого объекта системного анализа; выделение системных форм объекта по характеристикам сложности, разнообразия и упорядоченности; определение основных форм поведения субъекта; представление стратегических форм прогнозирования развития системы [9].

Формообразование системы связывается с общими процессами интериоризации и экстериоризации учебно - профессиональной широкопрофильной деятельности. При этом возникает ориентационная форма этапа, мотивационная форма этапа, визуальная форма этапа, акустическая форма этапа, калориметрическая форма этапа, термодинамическая форма этапа, обонятельная форма этапа, материальная форма этапа, рецепторная форма этапа, речевая форма этапа; письменная форма этапа, внутренняя форма этапа.

В целом выделяются две глобальные формы девятого действия системного анализа по определению формы организации системы: теоретические и практические формы. Проблема теоретичности формы системного анализа отражает единство теоретической триады: психологической теории деятельности, психолого-педагогического системного анализа и теории поэтапного формирования интеллекта. Теоретическая форма объекта рассматривается в трёх основных направлениях: определение теоретической формы современного производства с анализом целостно-системного цикла жизнедеятельности; управление теоретической формой системного анализа в направлении его психолого-педагогической составляющей; воспитание целостно-системной формы личности относительно выделенных форм её развития

Это открывает развитие и практической формы учебно-профессиональной жизнедеятельности, когда формируются начальные условия широкопрофильной личности, владеющей всеошей формой жизнедеятельности, направленной на интегральные практические формы средств жизнедеятельности, через организацию заданной практической формы технологической жизнедеятельности, владеющей анализом практического формообразования уровня системы, устанавливающей форму развития уровня с представлением форм структурных элементов и определённых практических форм системообразующих внутри и межуровневых связей, связанных интегральной и дифференциальной практической формой развития системы относительно сложности, разнообразия и упорядоченности системных характеристик практических форм системности, задающих практические формы статического и динамического поведения системы относительно практико-прогностической функции развития системы жизнедеятельности.

Теоретические и практические формы существования и развития целостно-системной личности формируют и практические формы смыслообразования основных видов системообразующих деятельностей производства Мира.

Действие десятое. Установить системные свойства объекта.

Психолого-педагогический системный анализ определяет базисные условия и формирует метод подготовки специалиста широкого профиля - формы организации целостно-системного учебного процесса. Десятым базисным действием психологопедагогического системного анализа является процесс установления системных свойств объекта.

Системные свойства объекта есть параметры и характеристики, которые отражают единство внутренних и внешних структур, особенности функциональных и конструкционных особенностей, глобальное сочетание целостных свойств объекта и результатов проявления порождающей среды, направленных на совершенствование и развитие пространственных, временных, гравитационных, силовых, энергетических, ориентационных, исполнительных, контрольных значений системы, развивающейся к совершенной целостности. Результатом этого процесса является формирование развивающихся системных свойств, которые отражают упорядоченность, разнообразие и сложность объектов относительно базисных, фундаментальных широкопрофильных характеристик [3].

Процесс установления системных свойств объекта по характеристике упорядоченности раскрывает процесс развития относительно всей структуры целостно-системного цикла жизнедеятельности и отражает: системные особенности субъекта процесса, генезис обобщённой целостно-системной деятельности, характеристики средств широкопрофильной деятельности, параметры и условия заданной технологической деятельности, базисные виды предметов фундаментальной деятельности, последовательность контрольной учебнопрофессиональной деятельности, обобщённые образы продуктов данного вида деятельности, особенности ритуальной деятельности, характеристики опредмеченной потребности, 
параметры восходящей деятельности цикла, системные особенности компаунд-субъекта процесса, последовательность деятельности развития, обобщённые образы нового суперсубъекта жизнедеятельности.

Особенности определения системных свойств объекта по характеристике разнообразия устанавливают процесс развития относительно всей структуры формирования целостносистемного цикла жизнедеятельности и выделяет: ориентационные характеристики объекта, мотивационные свойства системы, визуальные системные характеристики процесса, акустические параметры целостного объекта, калориметрические свойства системного цикла, термодинамические особенности существования и развития системы, обонятельному виды и формы характеристик объекта, материальные обобщённые образы цикла, рецепторные особенности системы, речевые формы инвариантно-обобщённых фонем, письменнографические представления системы, внутренние формы существования системы [8].

Процесс установления системных свойств объекта по характеристике сложности раскрывает процесс развития относительно всей структуры целостно-системного цикла жизнедеятельности и отражает: выделение объекта как системы, установление порождающей среды, определение целостных свойств системы, выделение уровней анализа, установление структурных элементов уровня, определение внутриуровневых системообразующих связей, выделение межуровневых системообразующих связей, установление формы организации, определение собственных системных свойств, выделение характера поведения и установление перспективы развития цикла. При этом, собственная сложность объекта определяется как единство целостных параметров объекта в условиях выполнения заданных функций от статического до динамического поведения системы в условиях автоматизированного управления процессами.

Развитие микроанализа психологической теории деятельности показывает, что базисные компоненты действия - ориентировка, исполнение и контроль, имеют сложную структуру и зависят от целостности каждого. Формирование системного типа ориентировки порождает и соответствующие компоненты заданой характеристики системных свойств. То есть существуют ориентировочные компоненты по характеристикам упорядоченности, разнообразия и сложности. Они определяют условия формирования последующей части десятого системного действия относительно исполнительной части действия в условиях упорядоченности, разнообразия и сложности. Это предопределит третий компонент системного действия по установлению системных свойств объекта относительно его завершающей части контрольные функции относительно упорядоченности, разнообразия и сложности [7].

Применение системного действия по установлению системных свойств объекта в условиях учебного процесса устанавливает новую экспозицию как самого учебного предмета, но и совершенствование форм организации познавательной деятельности относительно её типологии. Например, наращивание учебного материала интенсивными методами можно заменить формированием самого метода системного анализа в начале как предмета познания, а в дальнейшем - средством учебной деятельности по определению системных характеристик компонентов учебного предмета относительно упорядоченности, разнообразия и сложности. Это приводит и к более совершенной типологии учебных задач и практических заданий лабораторного практикума, когда анализируются выделенные проблемы также относительно упорядоченности, разнообразия и сложности.

Это системное действие порождает новый класс пакетов прикладных учебных компьютерных программ, когда формируется единая картина обобщённой естественной, технологической и интеллектуальной действительности в условиях многомерного единства множеств гиперпространств целостносистемной жизнедеятельности относительно упорядоченности, разнообразия и сложности смыслоообразования специалистов широкого профиля.

Действие одиннадцатое. Определить поведение системного объекта.

Психолого-педагогический системный анализ устанавливает базисные условия и определяет структуру подготовки специалиста широкого профиля - особенности развития целостно-системного учебного процесса. Одиннадцатым базисным действием психологопедагогического системного анализа является процесс определения поведения системного объекта.

Поведение системного объекта есть процесс не простого функционального взаимодействия между структурными элементами через системообразующие связи, а сложное постоянное развитие всей системы к всеобщей целостности. Это проявляется в совершенствовании глобальных связей с активно развивающей средой в совершенствовании всех целостных свойств относительно пространственных, энергетических, временных, гравитационных, силовых, ориентационных, исполнительных и контрольных параметров. Поведение объекта также рассматривается в направлении развития 
всей базисной структуры всего целостносистемного цикла жизнедеятельности (ЦСЦЖ), а также структурных элементов процесса системного анализа и форм развития смыслообразования.

В целом, рассматриваются два основных состояния поведения - статическое и динамическое, при этом выделяют четыре переходных состояния: статическая статика, статическая динамика, динамическая статика и динамическая динамика, которые определяют рубежные и переходные формы развития и функционирования всего гиперпространства различных ЦСЦЖ. Определим выделенные базисные и переходные формы состояния и функционирования системного объекта в условиях поэтапного и автоматизированного управления [4].

Статическое поведение системного объекта определяется выполнением всех целевых функциональных действий в условиях минимальной взаимосвязи с окружающей активной средой и объектами управления. При этом происходит начальная ориентировка всех структурных и системообразующих связей относительно многоуровневого целостного развития относительно целостных параметров. Переходным сигналом к выполнению всего статического поведения является анализ результатов соответствия относительно системных характеристик объекта в параметрах упорядоченности, разнообразия и сложности. Абсолютный контроль выделенных параметров предопределяет возможность поэтапного перехода к различным динамическим формам поведения объекта.

Переход к динамическому состоянию поведения системы указывает на возможность войти в условия максимальной эффективности функционирования всех структурных элементов и системообразующих связей относительно гиперцели развития системы. В данном случае возникает возможность мгновенного воздействия на все целостные и системные параметры относительно формы существования и управления объектом. Это проявляется в выходе системы на максимально возможные характеристики в условиях эффективных логистических функций, которые определяются минимаксными и максоминными условиями мгновенной адаптации системы. Это порождает новый класс профессиональных задач трёх категорий: структурные, функциональные и адаптивные.

Поведение системы в условиях статической статики задаётся определением тех сверхбазисных компонентов, которые формируют начальные целостные и системные характеристики объекта относительно определённых структурных элементов и системообразующих связей с выделенной формой организации. При этом определяются меры поэтапного развития и формирования системы относительно её будущей целостности в условиях дискретной меры всех порождающих элементов среды, целостных свойств объекта, его структурных элементов в выбранных системообразующих связях, межуровневых отношений, формы организации, системных свойств и поведения в статической статики относительно будущего смыслообразующего развития [9].

Дальнейшее развитие поведения системы определяется статической динамикой, которое характеризуется поведением объекта в условиях локального стабильного развития. В этих условиях начинается смещение предметных условий деятельности в средства деятельности, то есть происходит элементарное самонаучение объектов системы. Этот принцип заложен в самом развитии системы относительно её целостно-системных свойств статически динамического поведения. Выполнение заданных программ ЦСЦЖ выполняет больше по второму типу ориентировки, то есть с незначительным представлением полной ориентировочной основы деятельности. Контроль статически динамического поведения отражает уровень автоматизации целостно-системного развития.

Динамически статическое поведение системного объекта характеризуется развитием полного спектра функционирования всего ЦСЦЖ относительно базисной совокупности целостных и системных свойств. При этом раскрываются новые интегральные и дифференциальные характеристики объекта относительно многоуровневого строения, структуры уровня, характера системообразующих связей и межуровневых отношений, а также формы организации и перспектив развития. Контроль динамические статического поведения выделяет максимальные смещения динамических и статических характеристик, при которых возможно дальнейшее управляемое состояние объекта в условиях автоматизированного производства с минимаксными экономическими рисками.

Поведение системы у условиях динамической динамики характеризуется сверхбыстрыми процессами в условиях нечёткой логики и неопределённости. Это характеризует объект управления как самоуправляющую систему в условиях хаоса. При этом хаос выступает относительной мерои неопределённости в условиях сверхбыстрых процессов. Знание всеобеей структуры производства в условиях динамической динамики, метода системного анализа 
действительности, формообразование смысловой жизнедеятельности - порождает возникновение сверхбыстрых процессов функционирования системных объектов и возникновение сверхгиперпространства ЦСЦЖ, взаимосвязанных ноосферными формами акмеологического развития общества.

Действие двенадцатое. Установить прогноз развития системного объекта.

Психолого-педагогический

системный анализ определяет базисные предпосылки и условия структурной подготовки специалиста широкого профиля - главной формы развития целостно-системного учебного процесса. Двенадцатым базисным действием психологопедагогического системного анализа является процесс установления прогноза развития системного объекта.

Общее направление целостно-системного прогнозирования связывается с ведущим тезисом о том, что система в своём развитии стремится к целостности. Это определяется не просто аддитивными компонентами структурного переустройства объекта, а совершенствованием всех составляющих элементов относительно целостно-системных параметров: пространства, времени, гравитации, силовых отношений, энергии, ориентировки, исполнения, контроля, упорядоченности, сложности, упорядоченности. Это устанавливает новые качества порождающей среды, уровни анализа объекта, структурные элементы и системообразующие связи, а также соответствующие формообразования с заданными функциями статического и динамического поведения в данных условиях [5].

В целом, это устанавливает три стратегические направления развития прогностической деятельности: 1) совершенствование всеобщей структуры производства; 2) определение совершенной структуры целостно-системного цикла жизнедеятельности; 3) установление совершенной формы существования и формирования системной ориентировки в любой форме предметной деятельности. Это устанавливает новый класс адаптивных задач относительно любого действия системного анализа в целостно-системного цикла.

Развитие прогностической деятельности относительно совершенствования всеобщей структуры производства определяется анализом основных элементов: субъекта, средств, предмета и продукта производства, связанных функциональными составляющими - всеобщей, технологической и контрольной деятельностями. Их системное единство порождает новые формы активности, направленные на сокращение всех целостно-системных связей и формированием высокоскоростных двигательных навыков, пронизанных системным типом ориентировки в компонентах цикла жизнедеятельности. Основное направление прогностической деятельности управляется созданием оптимальных структурных отношений между предметными и функциональными компонентами.

Субъектный элемент развивается в направлении акмеологической смыслоориентации. Средства деятельности приобретают универсальные полисистемные функции. Предмет деятельности имеет универсальные формы, направленные на сокращение дифференциальных характеристик. Продукт деятельности приобретёт интегральные минимаксные и максоминные свойства. Всеобщая деятельность примет универсальные полисоциальные формы, направленные на функционирование сложных производств. Технологическая деятельность определит базисные направления сокращения многократных операций. Контрольная деятельность создаст универсальные формы мониторинга относительно развивающихся целостно-системных характеристик [10]. структуры целостно-системного цикла жизнедеятельности (ЦСЦЖ) совпадает с дальнейшим развитием как основной части производства так и собственной структуры процесса самосовершенствования. Процесс совершенствования структуры ЦСЦЖ происходит в двух направлениях 1) формированием целостно-системного скоростного смыслоообразования и 2) развитием целостно-системной ориентировки в различных видах деятельностных компонентов. При этом происходит формирование целостно-системных базисных циклов жизнедеятельности, которые отражают гиперпространства коммуникативных профессиональных отношений относительно всеобщего развития.

Опредмеченная потребность будет получать дополнительные целостно-системные характеристики связанные с развитием целостных параметров. Компаунд-субъект получает дополнительное развитие в направлении системных характеристик упорядоченности, разнообразия и сложности. Новый суперсубъект формирует общий банк развития целостно-системной личности, профессиональном образом которого является специалист широкого профиля. Ритуальная деятельность принимает новые целостноинтегральные характеристики относительно смыслоообразования. Восходящая деятельность задаётся сложными целостно-системными отношениями заданной формы. Деятельность 
развития определяет технологию формирования суперсубъектной личности.

Развитие прогностической деятельности относительно установления совершенной формы существования и формирования системной ориентировки в любой форме предметной деятельности определяет совершенствование процесса экстериоризации специалиста широкого профиля. Применение активных форм формирующих воздействий направляется на все органы чувств. При этом возникают дополнительные ощущения, направленные на формирование как субъектного, так и двигательного образа заданного параметра. Применение дополнительных характеристик порождающей среды определяет усиление формирующих факторов относительно целостносистемных характеристик, которые возникают в широкопрофильной профессиональной деятельности [6].

Ориентационный этап принимает короткодействующие динамические характеристики. Мотивационная форма развития имеет сверхтонкие целостно-системные отношения. Визуальное восприятие процесса ориентируется даже на смыслообразующие компоненты действия. Акустическое восприятие способно фиксировать сверхнизкие и ультравысокие информационные потоки. Калориметрические образы обладают широким спектром целостно-системных параметров. Все совершенные формы интериоризационного процесса связанные с обонятельными процессами, материальным восприятием, речевой деятельностью, знаковыми формами и внутренним чувством определяют направление прогностической деятельности психологопедагогического системного анализа. Действие первое. Выделить объект изучения как систему.

Психолого-педагогический системный анализ занимает базисную позицию в формировании целостно-системной личности и её профессионального образа - специалиста широкого профиля. Вместе со всеми двенадцатью действиями психолого-педагогического системного анализа первое базисное действие «Выделить объект изучения как систему» обеспечивает абсолютную рефлексию относительно внутренней и внешней среды всей совокупности действий системного анализа и является своеобразной «Азбукой Жизни» относительно всех форм активности субъекта образовательного пространства [1].

\section{References:}

1. Mishchik SA (2014) Pedagogometrika and mathematical modeling educational activity. Materialy Mezhdunarodnoy nauchnoy konferenctsii "Modern mathematics in science" - 30.06.2014. ISJ Theoretical \&Applied Science 6(14): 54-56 Caracas, Venezuela. doi: http://dx.doi.org/10.15863/TAS.2014.06.14.10

2. Mishchik SA (2014) Simulation training activity methods of mathematical logic. Materialy Mezhdunarodnoy nauchnoy konferenctsii "Eurapean Science and Education" - 30.07.2014. ISJ Theoretical \&Applied Science 7(15): 72-74 Marseille, France. doi: http://dx.doi.org/10.15863/TAS.2014.07.15.13

3. Mishchik SA (2014) Mathematical modeling system integrity-cycle of life activity - first goal pedagogometriki. Materialy Mezhdunarodnoy nauchnoy konferenctsii "European Applied Sciences" - 30.08.2014. ISJ Theoretical \&Applied Science 8(16): 77-79. Aix-en-Provence, France. doi: http://dx.doi.org/10.15863/TAS.2014.08.16.13

4. Mishchik SA (2014) Mathematical modeling system integrity-curricular activities - the second problem pedagogometriki. Materialy Mezhdunarodnoy nauchnoy konferenctsii "European Innovation" - 30.09.2014. ISJ Theoretical \&Applied Science 9(17): 126-128 Martigues, $\quad$ France. doi: http://dx.doi.org/10.15863/TAS.2014.09.17.21

5. Mishchik SA (2014) Mathematical modeling holistic-systemic communicative activity - the third task pedagogometriki. Materialy Mezhdunarodnoy nauchnoy konferenctsii "European Scientific Achievements" 30.10.2014. ISJ Theoretical \&Applied Science 10(18): 45-47 Brighton, UK. doi: http://dx.doi.org/10.15863/TAS.2014.10.18.11

6. Mishchik SA (2014) Mathematical modeling integrity - system performance subject - fourth task pedagogometriki. Materialy Mezhdunarodnoy nauchnoy konferenctsii "Eurapean Science and Technology" 30.11.2014. ISJ Theoretical \&Applied Science 11(19): 51-54 Southampton, UK. doi: http://dx.doi.org/10.15863/TAS.2014.11.19.10

7. Mishchik SA (2015) Pedagogometrik - science and academic subject. Materialy Mezhdunarodnoy nauchnoy konferenctsii 


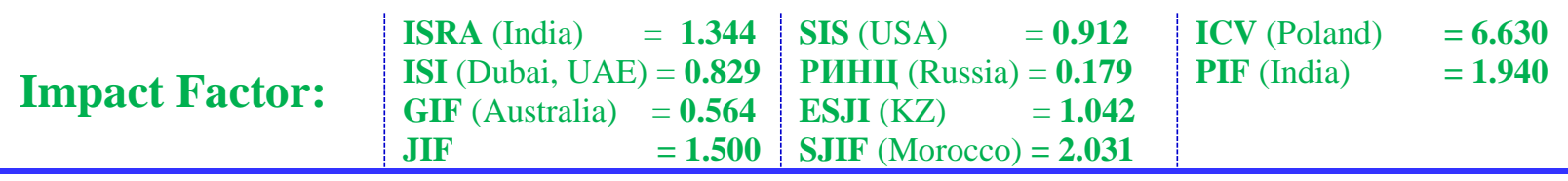

"European Technology in Science" 28.02.2015. ISJ Theoretical \& Applied Science 02 (22): 103-106 Malmö, Sweden. doi: http://dx.doi.org/10.15863/TAS.2015.02.22.17

8. Tokmazov GV (2014) Matematicheskoe modelirovanie $\mathrm{v}$ uchebno-professional'noy deyatel'nosti. Materialy Mezhdunarodnoy nauchnoy konferentsii «Modern mathematics in science» - 30.06.2014. ISJ Theoretical \& Applied Science 6(14): 44-46. - Caracas, Venezuela. doi: http://dx.doi.org/10.15863/TAS.2014.06.14.8

9. Tokmazov GV (2014) Analysis says study skills in the study of mathematics, Materialy Mezhdunarodnoy nauchnoy konferenctsii
"Eurapean Science and Education" 30.07.2014. ISJ Theoretical \&Applied Science 7(15): 72-74 Marseille, France. doi: http://dx.doi.org/10.15863/TAS.2014.07.15.14

10. Tokmazov GV (2014) Mathematical modeling research skills in educational activity methods of probability theory. Materialy Mezhdunarodnoy nauchnoy konferenctsii "Eurapean Science and Technology" 30.11.2014. ISJ Theoretical \&Applied Science 11(20): 66-69 Southampton, United Kingdom. doi:

http://dx.doi.org/10.15863/TAS.2014.11.19.13 